\title{
Second Language Acquisition as a Discipline: A Historical Perspective
}

\author{
Dr. Nabaraj Neupane
}

\begin{abstract}
Second language acquisition (SLA) generates and tests the theories concerning the acquisition of languages other than first language (L1) in different contexts. Even if SLA is a nascent discipline, its history is remarkable and helpful to seek the answers to the questions that researchers are raising in the field of second language or foreign language. Based on this context, this article aims to recount the history of the burgeoning discipline that heavily draws from numerous disciplines like linguistics, psychology, sociolinguistics, psycholinguistics, and so on. To achieve the objective, document analysis method has been used. The analysis and interpretation of the available documents exhibit that the traces of SLA were observed in the studies that address the issue of language transfer. Specifically, the diachronic study proves that the development of the discipline has undergone three evolving phases like background, formative, and developmental. The background phase caters for behaviourism, contrastive analysis hypothesis, and the attacks on the fundamental premises of behaviourism. The formative phase deals with Chomsky's revolutionary steps, error analysis, interlanguane theory, morpheme order studies, and the Krashen's monitor model that opened up the avenues for further studies of SLA. The developmental phase recounts various studies that have consolidated SLA as a separate discipline.
\end{abstract}

Keywords: behaviourism, error analysis, interlanguage theory, monitor model, second language

\section{Introduction}

Second Language Acquisition (SLA) is an emerging field of enquiry, developed from multiple disciplines like psychology, sociology, linguistics, pedagogy and the like (Mitchell \& Myles, 2004). It implies that SLA is not unidisciplinary but interdisciplinary as it borrows numerous concepts, views, ideas, theories, and practices from different disciplines. Yet, the nucleus of SLA began from the issue of the role of the native language (NL) in learning other languages. This central phenomenon is termed as language transfer, on which many theoretical underpinnings are associated with (Gass \& Selinker, 2009). Thus, the historical overview of SLA revolves around the key issue of language transfer, on which theoreticians have expressed their views for and against the notion. For example, early theorists like behaviourists and contrastive analysts suppose language transfer as a main source of errors whereas the latter theorists in the 1970 s and beyond the 1980s denied the key role of language transfer.

The post-war history of SLA is crucial to recount because numerous changes occurred after 1950s are responsible for the foundations of SLA as a burgeoning discipline. Therefore, Mitchell and Myles (2004) have divided the history of SLA in three different periods as: the 1950s and 1960s, the 1970s, and the 1980s and beyond. The first phase witnessed the developments of behaviourism, structuralism and contrastive analysis hypothesis, which firmly believed on the role of NL in the development of SL. The second phase 
began when Chomskyan revolution settled the role of mind in language acquisition. This term reshaped the concept of NLA and SLA and the by-product was error analysis. Chomskyan compartmentalized view also did not last long as a panacea for language learning process. The third phase, i. e. the 1980s and the beyond witnessed radical paradigm shifts in the domain. Basically, empirical evidences propelled by Morpheme Order Studies and a conceptual framework developed by Krashen's Monitor Model are landmarks to develop SLA as an autonomous house of many rooms.

Similar division is apparent in Gass and Selinker's (2009) work, too. For them, historical overview of SLA can move around the concentric rings of behaviourism, contrastive analysis hypothesis, error analysis and the recent perspectives. Based on these contexts, this article reviews, analyses, and interprets the history of SLA in three phases such as background, formative, and developmental.

\section{Methodology}

The main objective of this article is to explore the trails, on which SLA has come through for its development as a separate discipline. To achieve this goal, I have adopted document analysis method (DAM) that lies under the umbrella of qualitative approach. DAM analyses available documents within the domain selected (Krippendorff, 1980 \& Bell, 1999, as cited in Al-Jardani, 2012). Accordingly, this study has selected the domain of SLA history from the 1950s to the present day world. I have gone through the documents and analyzed the contents related to the framework (three phases) designed to draw inferences.

\section{Review and Analysis}

This section reviews, analyses, and interprets the SLA diachronically in terms of three evolving phases like background, formative, and developmental.

\section{Background Phase}

Background phase prepares ground for the formation of notions and theories that underpin SLA as an insular discipline. This phase begins with behaviourism (basically a theory of psychology), which made a debut as a linguistic equivalent to structuralism and the behaviouristic view (Mitchell \& Myles, 2004; Gass \& Selinker, 2009; Saville-Troike, 2010; Gass, Behney \& Plonsky, 2013). This view assumes that language is a set of habits and learning is to set the habits in the learners. This can also be called S-R-r model, in which a response to a stimuli is either strengthened or weakened by the absence or presence of reinforcement. For example, if a child is asked to recite the rules of the uses of the definite article 'the' and if he is promised to give a candy bar, he does the task. If the candy bar is given after his accomplishment, he continues his task, otherwise leaves it. For Mitchell and Myles's (2004) words, “The learning of any skill is seen as the formation of habits, that is, the creation of stimulus-response pairings, which become stronger with reinforcement" (pp. 30-31). Thus, language is considered a set of habits and learning as setting habits.

The contexts of native language acquisition (NLA) and second language acquisition (SLA) differ. The mind of NL learner is blank and therefore the learner sets a new habit by responding to the natural stimuli. However, the mind of SL learner is pre-occupied by a set of NL habits and to learn SL is to instill with another set of SL habits. NL, in this latter context can facilitate or inhibit in forming new habits. When similarities occur in NL and SL, the learner develops new SL habits as he did in NLA. However, in case 
of differences, NL interferes in SLA. The notion of similarity and difference is conceptualized by the term 'language transfer' (Mitchell \& Myles, 2004; Gass \& Selinker, 2009; Saville-Troike, 2010; Gass, Behney \& Plonsky, 2013), which is of two types such as positive and negative. The former case occurs when similarities occur whereas the latter occurs when discrepancies appear. For example, when Nepali learners of English learn nasal sounds like/m, n, $\eta$ /, they can easily learn. However, for them, learning labio-dentals like/f, v/ may impose difficulty as their sounds are bilabial in Nepali language. Thus, transfer theory has two pedagogical implications: (a) "Practice makes perfect", and (b) "Focus on [...] structures which were believed to be difficult" (Mitchell \& Myles, 2004, pp. 32-33). This quotation confirms that SL language teachers should emphasize on the points of differences in teaching because they can be the causes of errors.

The notion of discrepancies-cause-difficulties was termed contrastive analysis (CA), which drew heavily on behaviourism as a psychological basis and structuralism as a linguistic foundation. CA hypothesis was pioneered by C. C. Fries (1945) and Robert Lado (1957). CA hypothesis, for them, has two components like linguistic (based on structuralism) and psychological (based on behaviourism). The CA hypothesis assumes learning a mechanical process and language transfer as a key notion of SLA. The conceptualizations of this hypothesis were blurred by Chomsky's (1957, \& 1959) advent in the domain.

To substantiate the notion of behavior, Skinner published a book in 1957 entitled Verbal Behaviour. It was a coincidence that in the same year, Chomsky published a book Syntactic Structures, which laid foundation to mentalistic theories (Mitchell \& Myles, 2004). Further, Chomsky published a review on Skinner's book in 1959 that was a critique (on the fundamental premise of behaviourism) on two grounds: (a) Creativity of language and (b) Plato's problem (Chomsky, 1987, as cited in Mitchell \& Myles, 2004). The first criticism is that language learning is not so mechanical to acquire in a parrot-learning fashion; but it is a creative process in which rules are generalized. The evidence for this claim can be the irregular forms like *goed, *becomed, *writed, *runned, among others. Such ill-forms are not used by the competent speakers but the learners' forms are made by adding '-ed' in the base forms. Likewise, the second criticism is oriented towards a child language acquisition in which a child gets mastery over his NL in a short span of time. It is not less than a person (Hercules) who could hold a sky with a Finger (as mythology goes on). In Chomskyan terms, language is abstract rule-governed system which cannot be acquired only by imitating, repeating, memorizing and practicing. Had the learners not been equipped with their innate disposition to the principles and parameters of languages, NLA within a few years would not have been possible to acquire substantially. Chomsky's critique on Skinner's position, as a breakthrough in conceptualization of mental process of learning, gave a huge impetus to psycholinguistics, typically in NLA and SLA.

\section{Formative Phase}

Chomsky's revolutionary steps called for investigations in the domain of NLA, which were related to SLA. Mainly the empirical studies of Klima and Bellugi (1966), Slobin (1970), Cazden (1972) and Brown (1973), and the like gave a huge impetus to conclude that the order of NL acquisition is similar disregarding the learners' linguistic backgrounds (Mitchell \& Myles, 2004). This notion of natural order has been justified by Ellis' (1994) exemplification, in which acquisition of negatives pass through these 
three phases: external negation (e.g. no go out), internal negation (e.g. they no play), and finally negator attachment to modal auxiliaries (e.g. they can't play).

The findings in NLA research works in the 1970s showed the following characteristics (Mitchell \& Myles, 2004, p. 37):

- Children go through stages

- These stages are very similar across children for a given language, although the rate at which individual children progress through them is highly variable

- These stages are similar across languages

- Child language is rule-governed and systematic and the rules created by the child do not necessarily correspond to adult ones

- Children are resistant to correction

- Children's processing capacity limits the number of rules they can apply at any one time, and they revert to earlier hypotheses when two or more rules compete.

These features of NLA support Chomsky's notion of innate endowment of internal mechanisms in language acquisition device (LAD) or universal grammar (UG), which is supposed to consist of underlying principles and parameters to construct surface structures of any natural language.

The findings in NLA, characterized above, gave a great stimulus to the SLA researchers. Further, CA predictions (similarity causes ease but difference causes difficulty) were proved faulty. In other words, the languages having similar constructions could pose difficulty and the different constructions could pose ease. The distraction to CA and NLA findings resulted in the emergence of Error Analysis (EA), which investigates SL learners' errors systematically. Corder (1967) was the first scholar to see learners' errors significantly and to recognize errors to be committed only by the SL learners. Since then, the concept of CA, which viewed SL errors as the result of NL interference, was refuted. In this connection, Ellis (1985) found variations in the findings ranging from $3 \%$ to $51 \%$ errors were caused due to first language interference. This implies that majority of SL learners' errors are not attributed to their native languages. This shows that there are other causes on the occurrence of the errors, like analogical creation, overgeneralization, and hyper-correction. Those causes are related to the SL system. In this way, EA was focused to study only the errors but not the features of those errors. To fill this gap, Selinker (1972) introduced a term Interlanguage (IL) to characterize the learner's language to be systematic, dynamic, and permeable (Ellis, 1992). IL, thus, is a distinctive learners' language which comes in between NL and SL (termed as interlanguage continuum). However, IL does not completely reflect either of them. It is like a pidgin in the background phases and a creole in later phases of the continuum. In this continuum, the learner is open to reform or modify his/her hypothesis he/she makes in the earlier stages. It is also systematic.

Empirically significant contributions were traced in morpheme order studies in the IL stage of the SL learners. Of them, the most important studies were of Brown (1973), Dulay and Burt (1973, 1975, \& 1982), Bailey, Madden, and Krashen (1974); and, "thus, the 1970s witnessed a wealth of studies investigating development in second language learners that seemed to show convincingly that it is systematic, that is largely independent of the first language of the learner" (Mitchell \& Myles, pp. 43-44). Thus, morpheme 
order studies in the 1970s lay strong foundations to deduce the contemporary SL theories.

The first comprehensive model of SLA, developed by Krashen (although he has not mentioned it) in the early $1980 \mathrm{~s}$, is considered to be a point of departure for conceptualizing many issues raised in SLA. This pioneering work is termed as Krashen's Monitor Model, (Krashen, 1981, 1982, \& 1985) which comprises five basic hypotheses that are delineated in the succeeding paragraphs. This model was criticized for incomprehensibility and its theoretical nature after its arrival. However, this is the first point of departure to theorize SLA and many subsequent theories (like Interaction and Output hypotheses) and models are its by-products. Thus, its detailed delineation is considered worth mentioning in the succeeding sub-sections

The Acquisition-Learning Hypothesis. This is Krashen's main hypothesis which distinguishes acquisition with learning. Acquisition is supposed to be a sub-conscious process of acquiring meaning as its focus. In the contrary, learning is a conscious process of learning form as its focus. Further, the former occurs in natural setting whereas the latter in formal setting. The detailed distinction between the two phenomena is illustrated in table 1.

Table 1

Distinction Between SLA and SLL

\begin{tabular}{llll}
\hline \multicolumn{2}{l}{ SL Acquisition } & \multicolumn{2}{l}{ SL Learning } \\
\hline 1 & Similar to first language acquisition. & 1 & Formal knowledge of language. \\
2 & Knowing or picking up a language. & 2 & Knowing about a language. \\
3 & Sub-conscious process. & 3 & Conscious process. \\
4 & Implicit knowledge. & 4 & Explicit knowledge. \\
5 & Formal teaching does not play any role. & 5 & There is significant role of formal teaching. \\
6 & Occurs in natural setting. & 6 & Occurs in tutorial setting. \\
7 & Acquired knowledge is located in the left & 7 & Learnt knowledge is located in the left \\
& hemisphere of the brain in language areas. & & hemisphere of the brain but not in language \\
8 & Focuses on meaning. & & areas. \\
9 & Acquired knowledge initiates both production & 8 & Focuses on form. \\
& and comprehension. & 9 & Learnt knowledge is available for use only \\
& & & by monitors. \\
\hline
\end{tabular}

Source: Krashen, 1982, p. 83

Table 1 exhibits that acquisition and learning are separate to each other entirely. Krashen (1982) has claimed that learning (learnt knowledge) can never be converted into acquisition (acquired knowledge). This claim is observed between these lines (Krashen, 1982, p.83):

- Sometimes there is acquisition without learning that is, some individuals have considerable competence in a second language but do not know very many rules consciously;

- There are cases where 'learning' becomes acquisition, that is, a person can know the rule and continue breaking it; and 
- No one knows anywhere near all the rules.

Leaving out a few exceptions, learning cannot turn into acquisition. This is termed as "non-interface position" (Krashen, 1982, p. 83). This view is supported by Ellis (1985, p. 261) when he writes that acquired and learnt knowledge are separately stored, i.e., the former in left hemisphere and is available for automatic processing, whereas the latter is also stored in the same hemisphere but not necessarily in the language areas and is available only for controlled processing (which can be used only for use by monitor).

This hypothesis has been criticized on two grounds. The first is that conscious versus sub-conscious concepts/processes are vague, ambiguous and indistinguishable. The second ground is on non-interface position. However, many empirical studies have proved that because of rigorous practice, controlled processing can turn into automatic (McLaughlin, 1987). These limitations of this hypothesis reveal that Krashen's position is theoretical rather than empirical.

The Monitor Hypothesis. This hypothesis assumes that learnt knowledge monitors/edits the learners' language. In other words, learners' new knowledge checks and facilitates in modifying, justifying, falsifying or testifying their utterances created from acquired knowledge (Ellis, 1985). Hence, "The monitor is thought to alter the output of the acquired system before or after the utterance is actually written or spoken, but the utterance is initiated entirely by the acquired system" (Mclaughlin, 1987, p. 24). The claims are based on Krashen's (1985, p. 2) these views:

Our ability to produce utterances in another language comes from our acquired competence, from our subconscious knowledge. Learning, conscious knowledge, serves only as an editor, or monitor.

We appeal to learning to make corrections, to change the output of the acquired system before we speak or write (or sometimes after we speak or write).

These words reveal that learnt knowledge monitors the utterances generated from acquired knowledge, albeit monitoring may occur before or after their production. However Krashen (1981, p. 3) has specified these three conditions for monitor to act: (a) there must be sufficient time with language users; (b)the focus is on forms, not on meaning; and (c) the users know the rule. Krashen (1981) has also presented a typology of learner differences, based on monitor users. Over-users are those who are very continuous of making mistakes; under-users are those who are reluctant to monitor their utterances; and moderate/optimal users use monitor only when it is appropriate and needed. The third types, who are moderate users, may use the monitor only in writing but may not use it in speech.

Like the acquisition-learning hypothesis, monitor hypothesis has also been criticized. For Mitchell and Myles (2004) and McLaughlin (1987), the monitor hypothesis has been criticized for untestifiability of its predictions and difficulty in identifying whether the learner is using acquired knowledge or learnt knowledge. Further, for Ellis (1985), monitoring is applied for syntactic structures only, although the learners can edit phonological, semantic, pragmatic and discoursal patterns, and this model cannot address the collaborative activity between the learner and his communicators which proves to be crucial in SL development. Moreover, the monitor hypothesis contradicts with acquisition-learning hypotheses. The latter separates the two and claims that learned knowledge cannot turn into acquired one. However, the former hypothesis assumes initial SL utterances are generated from the acquired competence, and the 
learned knowledge monitors those utterances. This shows the relationship between acquisition and learning.

The Natural Order Hypothesis. Although unstated by Krashen himself, this hypothesis draws heavily on morpheme order studies conducted by Brown (1973), Dulay and Burt (1973, 1975 \& 1975) and the like (cf. Mitchell \& Myles, 2004). This hypothesis assumes that SLA takes place in a fixed order and hence it claims:

We acquire the rules of language in a predictable order, some rules trending to come early and others late. The order does not appear to be determined solely by formal simplicity and there is evidence that it is independent of the order in which rules are taught in language classes. (Krashen, 1985, p.1) This quotation reveals that SL rules are acquired in a sequential order but this order cannot altered even by the way learners are taught in formal setting. This also shows that SL learners follow the same order of acquiring rules of a language in an invariant order regardless of the learners' age, NL backgrounds, exposure, context and the like.

As the other hypotheses, the natural order hypothesis has also been criticized for being "too strong" and "based almost exclusively on the morpheme order studies with their known methodological problems" (Mitchell \& Myles, 2004, p. 47). Further, this hypothesis has been criticized for ignoring learner differences, roles of the learners' native language backgrounds and contextual factors that influence the SLA.

The Input Hypothesis. The Input Hypothesis draws on the natural order hypothesis as the later assumes the predictable order of acquisition that is possible only if input is intelligible to the learners. Krashen (1985) has claimed that "comprehensive input" (i+1) suffices second language acquisition (p. 2). This claim is reflected in these words:

Humans acquire language in only one way-by understanding messages, or by receiving 'comprehensive input' [...]. We move from $\mathrm{i}$, our current level, to $\mathrm{i}+1$, the next level along the natural order, by understanding input containing $i+1$.

(Krashen, 1985, p. 2)

Thus, if and only if input is understood and is in the grasp of the learner, acquisition takes place despite the complexity of the language in question. Further assumptions have also been asserted by Krashen (1985): (a) Speaking is a result of acquisition and not its course; and (b) If input is understood and there is enough of it, the necessary grammar is automatically provided (p. 2). These claims reveal that the obligatory condition for SL acquisition is the learners' exposure to $i+1$ but not only $i$ (which is too simple) nor can it be $i+2 / 3 / 4$ that becomes too complex and that breaks the natural order.

Like other hypotheses, the input hypothesis has been criticized for being ambiguous, too theoretical, and silent about the internal mechanisms of human brain where information is processed. Further, this hypothesis describes only about acquisition but not about learning.

The Affective Filter Hypothesis. Learners need to be exposed to comprehensible input for the occurrence of language acquisition. In other words, these should not be any obstruction, barrier, or inhibition to let the input in for language acquisition to take place. This barrier, in Krashen's (1985) term, is affective filter which blocks partially or wholly the input from entering into the language acquisition 
device (LAD). At this juncture, these words are worth quoting:

The Affective Filter Hypothesis captures the relationship between affective variables and the process of second language acquisition by positing that acquirers vary with respect to the strength or level of their affective filters. (Krashen ,1985, p. 31)

This entails that affective filters are determinants of low of more language acquisition. When the filter is strong/up/high, more input is blocked to be processed in LAD; and low acquisition takes place. On the contrary, when the filter is weak/down/low, input goes into the LAD directly, and more acquisition takes place. It is customary to note that affective variables comprise motivation, self-confidence, and anxiety that determine language acquisition. In this way, the filter influences in the rate/speed of acquisition but not its route.

As in the case of other theories, this hypothesis has also been criticized for being "vague and theoretical" (Mitchell \& Myles, 2004, p.48). Actually, the conceptualization of affective filter and its functions are to be explored with empirical studies.

In a nutshell, Krashen's Monitor Model comprises five interrelated hypotheses, which are untested. Therefore, many theorists, in the domain of SLA, have come up with new theories while criticizing this model. Thus, Krashen's model, although untested (and required to be tested), has been proved to be a point of departure for second language theories.

The late 1970s saw the emergence of new models. One of them is Schumann's pidiginization or acculturation model which assumes that, "Second language acquisition was compared to the complexification of pidgins, and this process was linked to degree of acculturation of the learners" (Mitchell \& Myles, 2004, p.49). This shows that early interlanguage is pidgin-like and it gradually becomes creole-like. If the acquirers are capable of acculturating to the target language community, they can be more successful SL learner; otherwise less successful (and their SL becomes more pidgin-like).

\section{Developmental Phase}

The third period is supposed to begin in the 1980s which drew heavily on the empirical findings of the 1970s. The research works in SLA domain and contributions of the other disciplines are attributing in the evolving series of the insular discipline of the SLA. Therefore, SLA has been an autonomous field of inquiry as it has a good wealth of theoretical underpinnings and empirical evidences to justify this claim. This claim is justified by the introduction of sociocultural theory, multidimensional model, processability theory, competition model, connectionism, constructivism, social constructivism, functional or pragmatic theories, and so on (Saville-Troike, 2010).

The research agendas of SLA, forwarded since the 1970s, revolve around these basic premises (Mitchell \& Myles, 2004, p. 50-51): (a) The role of internal mechanisms; (b) The role of the first language; (c) The role of psychological variables; (d) The role of social and environmental factors; and (e) The role of input. The internal mechanisms are associated to Chomskyan view of compartmentalization that believes on the existence of LAD/UG in the left hemisphere and Piagetian unitary view that assumes language and the complicated other skills are acquired in the same process. These views are also related to investigate the 
similarities and dissimilarities between NLA and SLA. The next research agenda of the day is to explore the phenomenon of language transfer. The third and the fourth agendas are to delve into the psychological, social, and environmental variables which count much in SLA. Finally, the role of input and interaction in SL development has been an issue for further exploration. As a result, SLA, now, has been a veritable gold mine for researchers and has been enriched with varying views, concepts, theories and perspectives like linguistic, sociolinguistic, socio-psychological, psycholinguistic, cognitive, neuro-psychological and functional/pragmatic, to mention a few. For this reason, SLA has been a house of many rooms now.

\section{Conclusion and Implications}

Second Language Acquisition has made its own space in the academia now. Its evolution can be traced in three phases like background, formative, and developmental. The first, i.e. background phase incorporates behaviourism, contrastive analysis hypothesis, and the critiques on the propositions of the first. The role of the first language transfer in second language acquisition is accepted, described and promoted by the behaviourists' theory to language learning, which was popular during the 1950s and the 1960s. The second, that is, formative phase subsumes Chomsky's revolutionary steps, error analysis, interlanguage theory, morpheme order studies, and the Krashen's monitor model. The Chomskyan revolution expanded and explained the role of mind to internalize the underlying universal features of language and to generate the noble utterances. The Chomskyan explanation of the role of mind was initially focused on the study of the first language acquisition and subsequently, on that of the second language acquisition. Similarly, the impact of SLA in psycholinguistics in the 1970s is another turn in the development of SLA as a distinct discipline. Out of the theories and models developed in the formative phase, the Krashen's model is significant as it opened up the avenues for further studies in SLA. The last, that is, developmental phase recounts various studies that have consolidated SLA as an independent discipline. The last phase includes from reactions of the Krashen's model to the latest perspectives like competition model, processability theory, connectionism, and constructivism, to mention but a few. In the recent decades from 1980s onwards, SLA has been developed as an autonomous field of inquiry supported by sociocultural, interlingual, cognitive, contextual and numerous other insightful perspectives. Therefore, SLA has settled itself as an independent discipline that has drawn heavily from adjacent fields of inquiry.

\section{References}

Al-Jardani, K. S. S. (2012). English language curriculum evaluation in Oman. International Journal of English Linguistics, 2 (5), 40-44. doi: 10.5539/ijel.v2n5p40.

Chomsky, N. (1957). Syntactic structures. The Hague: Mouton.

Corder, S. P. (1973). Introducing applied linguistics. Harmondsworth: Penguin.

Ellis, R. (1985). Understanding second language acquisition. Oxford: Oxford University Press.

Ellis, R. (1992). Understanding second language acquisition. Oxford: Oxford University Press.

Ellis, R. (1994). The study of second language acquisition. Oxford: Oxford University Press.

Gass, S. M., \& Selinker, L. (2009). Second language acquisition : An introductory course (3 ${ }^{\text {rd }}$ ed.). New York: Routledge. 
Gass, S. M., Behney, J., \& Plonsky, L. (2013). Second language acquisition: An introductory course (4 ${ }^{\text {th }}$ ed.). New York: Routledge.

Krashen, S. (1981). Second language acquisition and second language learning. Oxford: Pergamon.

Krashen, S. (1982). Principles and practices in second language acquisition. Oxford: Pergamon.

Krashen, S. (1985). The input hypothesis: Issue and implications. Harlow: Longman.

Krippendorff, K. (2013). Content analysis: An introduction to its methodology. USA: Sage.

Lado, R. (1957). Linguistics across cultures. Ann Arbor: University of Michigan Press.

McLaughlin, B. (1988). Theories of second language learning. London: Edward Arnold.

Mitchell, R., \& Myles, F. (2004). Second language learning theories ( $2^{\text {nd }}$ ed.). Great Britain: Hodder Arnold.

Saville-Troike, M. (2010). Introducing second language acquisition. New Delhi: Cambridge University Press.

Selinker, L. (1972). Interlanguage. International review of applied linguistics, 10, 209-31.

Dr. Nabaraj Neupane is a Reader (Associate Professor) in English Education at Tribhuvan University, Nepal. He is a teacher trainer and the President of NELTA Gandaki Province, Pokhara. He has been honoured with Nepal Vidhyabhusan Ka by Nepal Government. To his credit, more than five dozens of articles have been published in different journals from home and abroad. He has also published books, edited journals, translated literary texts, and presented papers in national and international conferences. His professional interests include Research Methodology, Translation Studies, SLA, Pragmatics, Discourse Analysis, and Use of ICT in ELT. 